\title{
The Coupled GCM ECHO-2. Part I: The Tropical Pacific
}

\author{
H. FREY AND M. LATIF \\ Max-Planck-Institut für Meteorologie, Hamburg, Germany \\ T. Stockdale \\ European Centre for Medium-Range Weather Forecasts, Shinfield Park, Reading, United Kingdom
}

(Manuscript received 16 June 1995, in final form 16 February 1996)

\begin{abstract}
In this paper the performance of the global coupled general circulation model (CGCM) ECHO-2, which was integrated for 10 years without the application of flux correction, is described. Although the integration is rather short, strong and weak points of this CGCM can be clearly identified, especially in view of the model's performance of the annual cycle in the tropical Pacific. The latter is simulated with more success relative to the earlier version, ECHO-1. A better representation of the low-level stratus clouds in the atmosphere model associated with a reduction in the shortwave radiative flux at the air-sea interface improved the coupled model's performance in the southeastern tropical oceans, with a strongly reduced warm bias in these regions. Modifications in the atmospheric convection scheme also eliminated the AGCM's tendency to simulate a double ITCZ, and this behavior is maintained in the CGCM simulation. Finally, a new numerical scheme for active tracer advection in the ocean model strongly reduced the numerical mixing, which seems to enhance considerably the level of interannual variability in the equatorial Pacific.

One weak point is an overall cold bias in the Tropics and midlatitudes, which typically amounts to $1^{\circ} \mathrm{C}$ in open ocean regions. Another weak point is the still too strong equatorial cold tongue, which penetrates too far into the western equatorial Pacific. Although this model deficiency is not as pronounced as in ECHO-1, the too strong cold tongue reduces the level of interannual rainfall variability in the western and central equatorial Pacific. Finally, the interannual fluctuations in equatorial Pacific sea surface temperatures (SSTs) are too equatorially trapped, a problem that is also found in "ocean-only" simulations. Overall, however, the authors believe that the ECHO-2 CGCM has been considerably improved relative to ECHO-1.
\end{abstract}

\section{Introduction}

Mechoso et al. (1995) described the seasonal cycle over the tropical Pacific simulated by eleven coupled ocean-atmosphere general circulation models (CGCMs). Some common errors were identified in that study, which stimulated further work on the development and tuning of CGCMs. We participated in the Mechoso et al. (1995) coupled model intercomparison with the first cycle of our CGCM, hereafter referred to as ECHO-1. The performance of ECHO-1 with respect to the mean state, annual cycle, and interannual variability during the first 20 years of a 125-yr integration is described in Latif et al. (1994) and some aspects of the simulated decadal variability over the North Pacific in Latif and Barnett (1994). The warm-pool physics in that entended-range integration with ECHO-1 are examined in Schneider et al. (1996).

Although the integration with ECHO-1 was generally

Corresponding author address: Dr. Mojib Latif, Max-Planck-Institut für Meteorologie, Bundesstrasse 55, 20146 Hamburg, Germany. E-mail: latif@dkrz.de considered a success, yielding a reasonable SST simulation without flux correction, a number of weak points were identified in that simulation. The most important of those pertaining to the model's performance in the Tropics are: a too strong equatorial cold tongue that extends too far into the western Pacific, the simulation of a double ITCZ over the Pacific, large SST errors in the southeastern tropical oceans, a too strong semiannual cycle in eastern equatorial Pacific SST, and too weak interannual variability in the tropical Pacific. These errors could largely be traced back to problems in the individual model components, although coupled feedbacks are important in amplifying some of these errors. As pointed out by Mechoso et al. (1995), for instance, one major problem in most coupled GCMs was the underestimation of the low-level stratus cloud cover in the atmosphere models, which inhibited a realistic simulation of the mean state and annual cycle in the tropical Pacific in coupled mode.

In this paper, we describe the second cycle of our coupled general circulation model, which will be referred to as ECHO-2. We improved the individual model components, and this improved considerably the cou- 


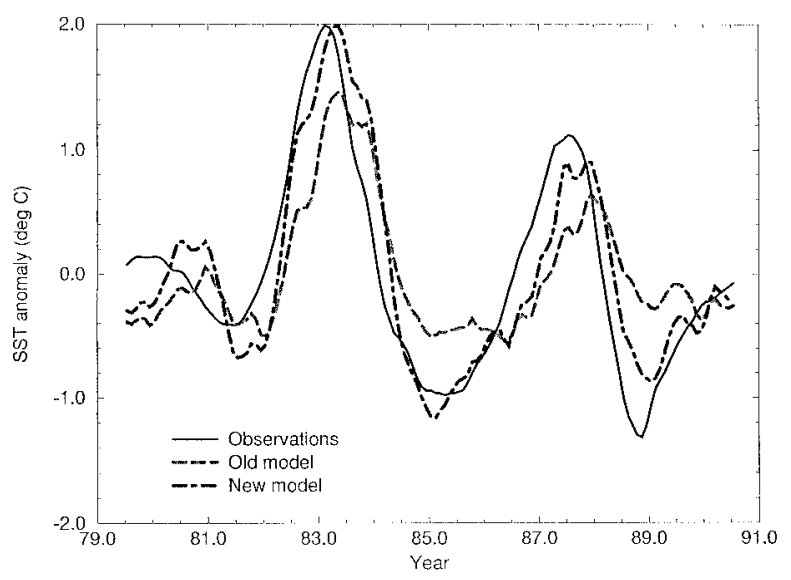

FIG. 1. Twelve-month running means of SST anomalies in the EQ1 region $\left(5^{\circ} \mathrm{N}-5^{\circ} \mathrm{S}, 90^{\circ}-130^{\circ} \mathrm{W}\right)$ for the period $1979-90$. Observations (solid line) compared to 12-yr runs of the new (HOPE-2) and old HOPE model (HOPE-1).

pled model behavior. Since the integration presented here has a duration of 10 years only, the bulk of the paper is devoted to the simulation of the mean state and annual cycle in the tropical Pacific. Both the mean state and annual cycle are good testbeds for coupled models, because they originate (at least partly)-like the El Niño-Southern Oscillation (ENSO) phenomenonfrom unstable air-sea interactions (e.g., Neelin 1991; Philander 1990; Dijkstra and Neelin 1995; Xie and Philander 1994). Furthermore, nonlinear interactions between the annual cycle and the fundamental ENSO mode appear to be crucial in explaining the phase locking and irregularity of ENSO (e.g., Chang et al. 1994; Jin et al. 1994; Tzipperman et al. 1994). Systematic errors in the simulation of the mean state and annual cycle become generally obvious after a few years of integration, since climate drift involves also relatively fast coupled feedback processes (e.g., Neelin et al. 1992). We also discuss some aspects of the simulated interannual variability, since strong and weak points can be clearly identified, even in this rather short coupled integration.

The paper is organized as follows. We describe the coupled model in section 2 . The simulated mean state is discussed in section 3, and the annual cycle simulated over the tropical Pacific is examined in section 4. Some aspects of the interannual variability are discussed in section 5. The paper concludes with a discussion of the results in section 6 .

\section{Coupled model}

The atmospheric component of our coupled GCM ECHO-2 is ECHAM-4, the latest Hamburg version of the European Centre operational weather forecasting model. The model is described partly in DKRZ (1995), Roeckner and Arpe (1995), and Roeckner (1995). The latter describes some of the most important changes made relative to ECHAM-3. ECHAM-4 is a global loworder spectral model with a triangular truncation at wavenumber 42 (T42). The nonlinear terms and the parameterized physical processes are calculated on a 128 $\times 64$ Gaussian grid, which yields a horizontal resolution of about $2.8^{\circ} \times 2.8^{\circ}$. There are 19 levels in the vertical, which are defined on $\sigma$ surfaces in the lower troposphere and on $p$ surfaces in the upper troposphere and in the stratosphere.

Several changes were made relative to the earlier cycle ECHAM-3 that was used in the studies of Latif et al. (1994), Latif and Barnett (1994), Schneider et al. (1996), and Mechoso et al. (1995). The changes were made basically to incorporate the advances in the understanding of certain physical processes and not to resolve particular problems that occurred in former coupled integrations. However, it is rewarding that the changes in the atmosphere model had also a beneficial impact on the coupled behavior. Most important to the coupled model performance are the changes in the radiation and convection schemes. The main changes are the application of semi-Lagrangian scheme for water vapor, cloud water, and trace constituents, a new radiation code (Morcrette 1991), the inclusion of cloud water detrainment in the stratiform cloud water equation, a higher-order closure scheme for vertical mixing within and above the atmospheric boundary layer (Brinkop and Roeckner 1995), a new closure for deep convection, a new formulation for organized detrainment (Nordeng 1997), and the linkage of marine stratocumulus clouds to the existence of a low-level inversion (Slingo 1987).

These changes improved considerably the simulation of the main tropical covergence zones, especially the South Pacific convergence zone (SPCZ). Furthermore, ECHAM-4 simulates more stratus clouds over the southeastern tropical oceans, which had a very beneficial impact on the coupled model performance, as described below. The atmosphere model ECHAM-4 was also coupled to another ocean circulation model, and first results of a 100-yr coupled integration are described by Roeckner et al. (1996).

The ocean model is "HOPE-2" (Hamburg Ocean model in Primitive Equations), which is based on primitive equations. Its domain is global and we use realistic bottom topography. The meridional resolution is variable, with $0.5^{\circ}$ within the region $10^{\circ} \mathrm{N}-10^{\circ} \mathrm{S}$. The resolution decreases poleward to match the $\mathrm{T} 42$ resolution of the atmosphere model. The zonal resolution is constant and also matches the atmospheric model resolution. Vertically, there are 20 irregularly spaced levels, with 10 levels within the upper $275 \mathrm{~m}$. Since we have not yet included a sea-ice model in HOPE-2, the SSTs are relaxed to Levitus (1982) climatology poleward of $60^{\circ}$, using a Newtonian formulation with a time constant 24 days for the upper-layer thickness of $20 \mathrm{~m}$. The vertical mixing is based on a Richardson number-dependent formulation and a simple mixed-layer scheme to 

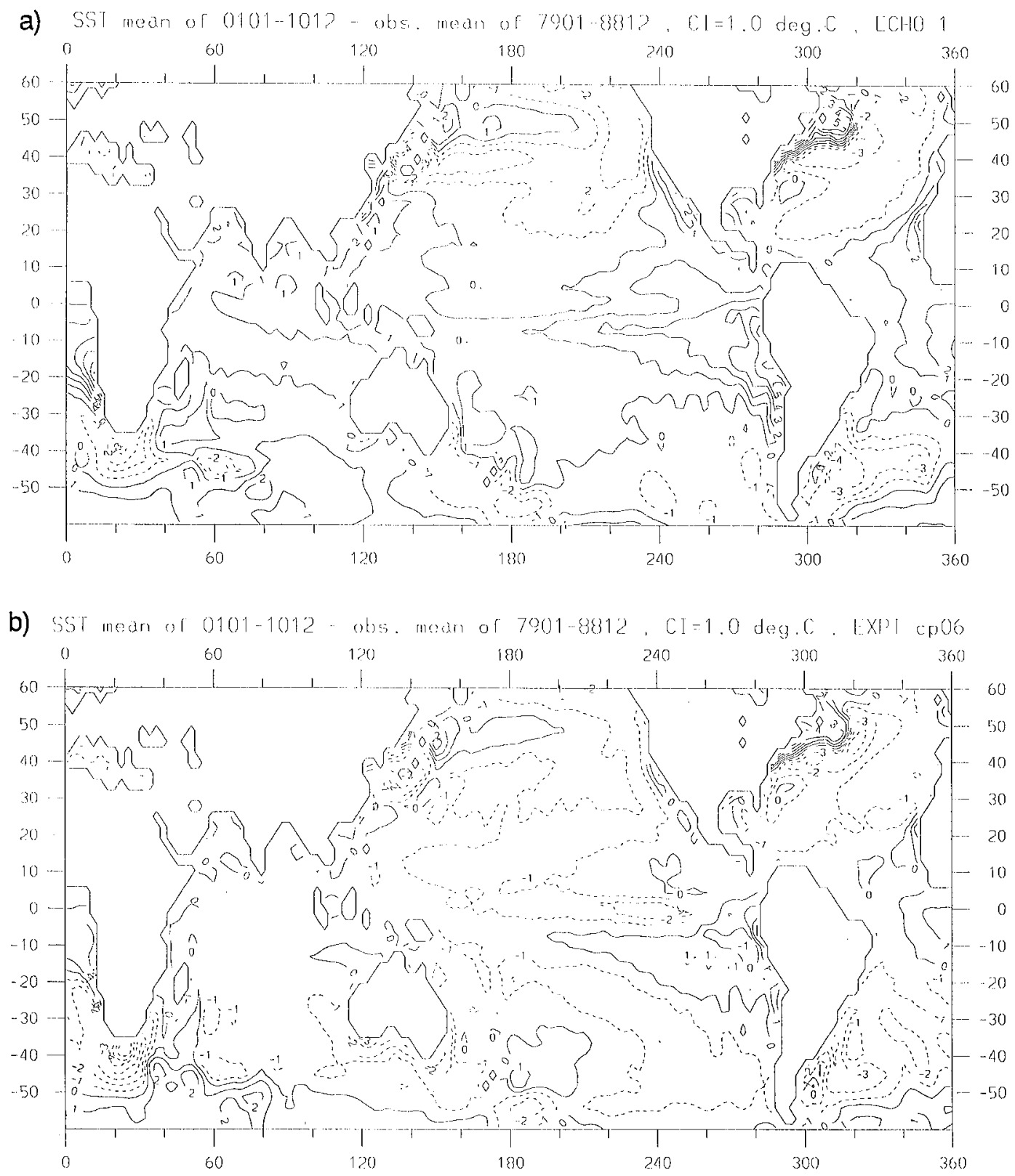

FIG. 2. Annual mean SST errors $\left({ }^{\circ} \mathrm{C}\right)$ derived from (a) the old coupled GCM ECHO-1 and (b) new coupled GCM ECHO-2. The contour interval is $1^{\circ} \mathrm{C}$. Negative contours are dashed.

represent the effects of wind stirring [see Latif et al. (1994) for details].

The HOPE model has also undergone substantial revision since the earlier coupled experiments described in Latif et al. (1994) and Stockdale et al. (1994). The most important change is that the advection of active tracers (salinity and temperature) now uses a centereddifference scheme rather than an upstream one. This has a big impact on the model because of the relatively large amount of high-frequency model variability, particularly along the equator. This in turn is related to the forcing given to the ocean model: daily fluxes in forced mode, and 2-h fluxes when coupled. The change in the advection scheme and the associated reduction in effective mixing weakened the Equatorial Undercurrent (EUC) substantially. To compensate, the momentum mixing parameterizations were retuned. Horizontal momentum mixing in the HOPE model is fairly complex, with contributions from harmonic, biharmonic, and strain-dependent terms. We use all three components for momentum mixing, while the mixing of scalar quantities is based on the harmonic part only. Each contribution can be implemented in normal or horizontally rotated form on the Arakawa E grid, and each implementation 

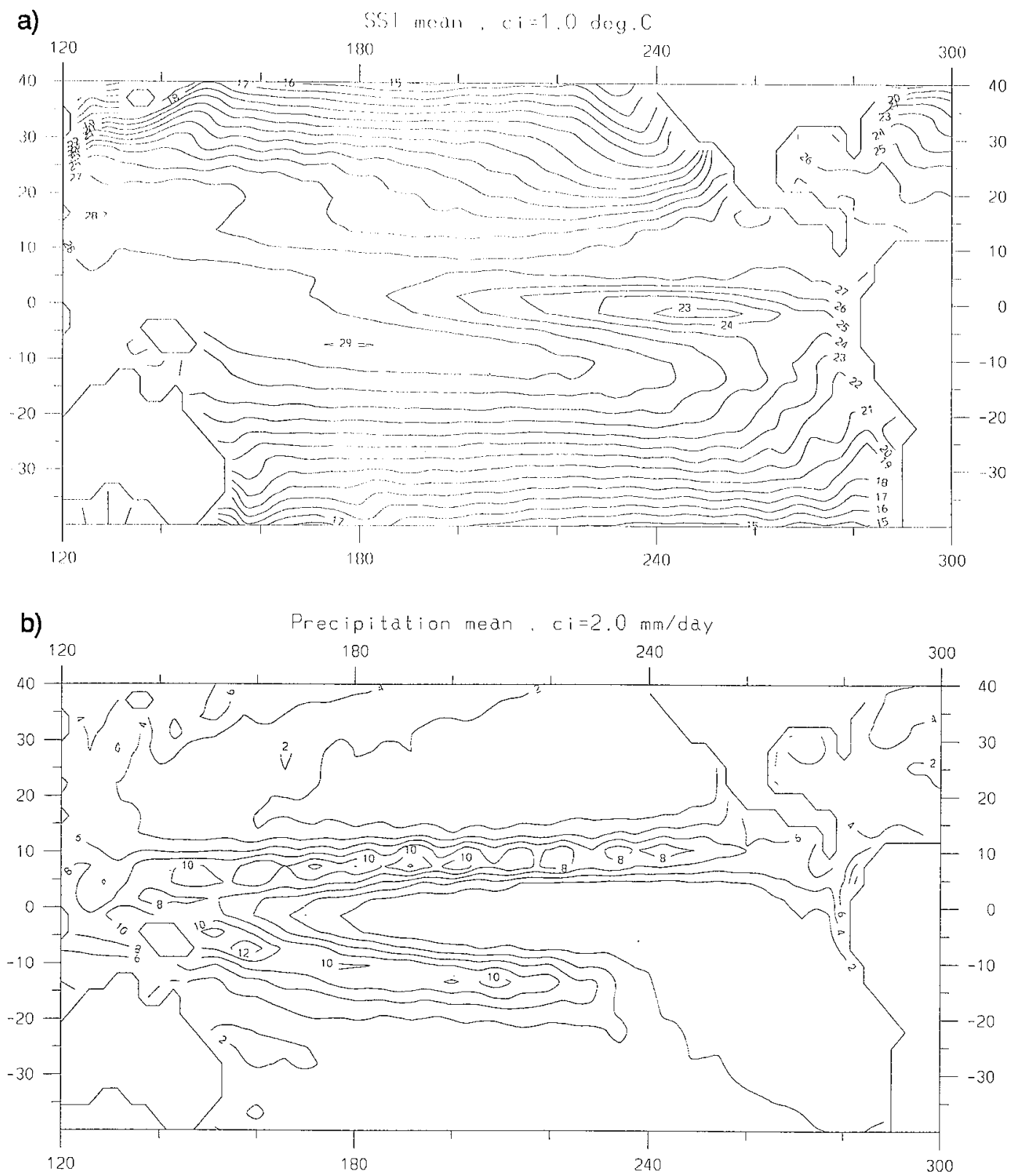

FIG. 3. Annual mean fields of tropical Pacific (a) SST $\left({ }^{\circ} \mathrm{C}\right)$, (b) precipitation $\left(\mathrm{mm} \mathrm{day}^{-1}\right)$, and (c) net surface heat flux $\left(\mathrm{W} \mathrm{m}^{-2}\right)$ as simulated by ECHO-2. The contour intervals are $1^{\circ} \mathrm{C}, 2 \mathrm{~mm} \mathrm{day}^{-1}$, and $20 \mathrm{~W} \mathrm{~m}^{-2}$, respectively. Negative contours are dashed.

can also be made using either a grid point or a true metric. Different combinations of these possibilities produce quite different behavior of the numerics and the EUC. There is also a strong interaction with the vertical mixing. The momentum mixing was tuned to produce as strong an EUC as possible, without it breaking down into Legeckis-type disturbances, which the model is unable to resolve properly.

A further change was made to the surface mixing scheme: this was given a smoother decay with depth of wind-driven turbulence in the case of deep mixed layers.
The result is slightly less mixing in most cases, and therefore a shallower mixed layer. Other changes to the model were numerous but minor, and included small bug fixes and improved conservation properties for very long runs. To help assess the importance of these changes to the ocean model, an uncoupled ocean simulation was made. This uses daily averaged surface fluxes from an AMIP-type integration with an atmosphere GCM to force the ocean model, and covers the period 1979-90. The fluxes came from the T42 version of ECHAM-3, the model that was used in the previous 


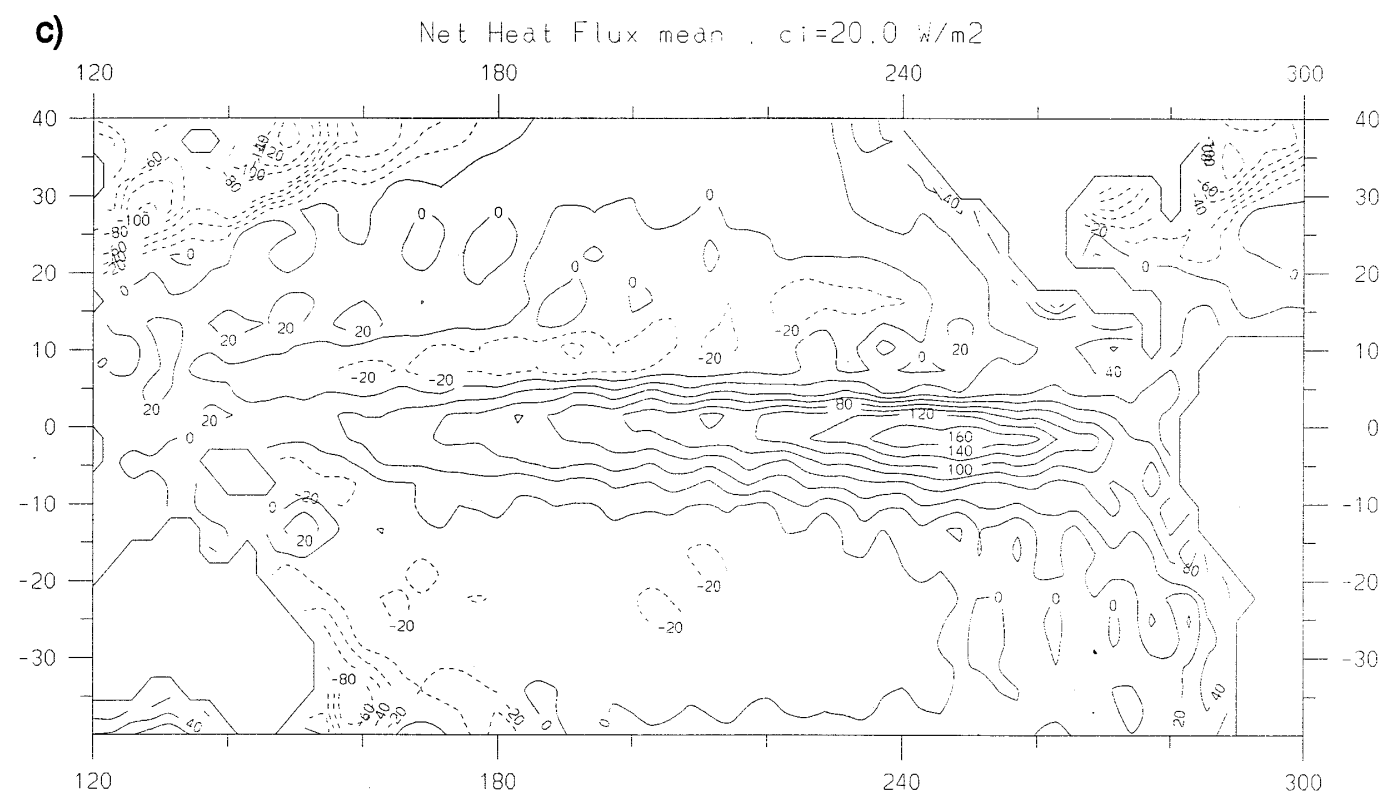

FIG. 3. (Continued)

version of the coupled system ECHO-1, and an identically forced simulation with the (original) HOPE-1 model will be used for comparison in this paper. In terms of the mean state, dramatic improvements are seen in the structure of the thermocline (much sharper in the new version HOPE-2) and in the mean surface temperatures along the equator (the strong cold bias of HOPE-1 is largely removed). The temporal structure of the mean seasonal cycle of SST in the eastern equatorial Pacific is hardly changed (correlation with the old model greater than 0.99), but its amplitude is increased, and is now overestimated by about $20 \%$. In the central west Pacific, however, the annual cycle is reduced in amplitude. This is more realistic, and presumably related to the much warmer mean state.

Interannual variability in HOPE- 2 is concentrated farther to the east, relative to HOPE-1, and is generally more realistic. The most notable improvement is in the EQ1 region, which is located in the eastern equatorial Pacific, $\left(5^{\circ} \mathrm{N}-5^{\circ} \mathrm{S}, 90^{\circ}-130^{\circ} \mathrm{W}\right)$, and is illustrated in Fig. 1. The 12-month running mean SST of the original model (HOPE-1) shows an apparent large phase lag with the observations. In fact, the model is producing a strong response to local wind stress forcing, while the remote response is weak. The new model has a much better simulation in the eastern Pacific, with the correlation of the 12-month running mean SST with observations increasing from 0.74 to 0.90 . The increased amplitude is also more in line with observations. The simulation is still not perfect, although some of the remaining error may be attributable to the wind field. Nonetheless, the new model appears to handle the equatorial thermodynamics much better than the old. This may well be related to its much sharper thermocline, which is be- lieved to be highly relevant to the ability of the model to produce realistic interannual variability in coupled mode, as described below.

The two models ECHAM-4 and HOPE-2 were coupled without applying flux correction. They interact over all three oceans in the region $60^{\circ} \mathrm{N}-60^{\circ} \mathrm{S}$. The ocean model is forced by the surface wind stress, the surface heat flux, and the freshwater flux simulated by the atmosphere model, which in turn is forced by the SST simulated by the ocean model. As described in Latif et al. (1994), solar radiation is allowed to penetrate beneath the first ocean layer. The coupling is synchronous, with an exchange of information every $2 \mathrm{~h}$. The coupled GCM is forced by seasonally varying insolation. The oceanic initial conditions are taken from Levitus (1982) climatology and those for the atmosphere model from a control run with climatological sea surface temperatures (SSTs). The coupled integration (labeled EXPT cp06) is started on 1 January and continued for 10 years.

\section{Mean state}

One key quantity by which the performance of coupled models can be evaluated is SST. We display in Fig. 2 the long-term annual mean SST errors relative to the mean SSTs observed during the (AMIP) period 197988 and in Fig. 3a the simulated annual mean SST in the tropical Pacific. The errors obtained in the coupled integration with ECHO-2 are shown in Fig. 2b, while those with ECHO-1 are shown for comparison in Fig. $2 \mathrm{a}$. The most obvious differences between the two coupled model simulations are found in the southeastern tropical Pacific and Atlantic Oceans. While SST errors amount to almost $6^{\circ} \mathrm{C}$ in the immediate vicinity of the 

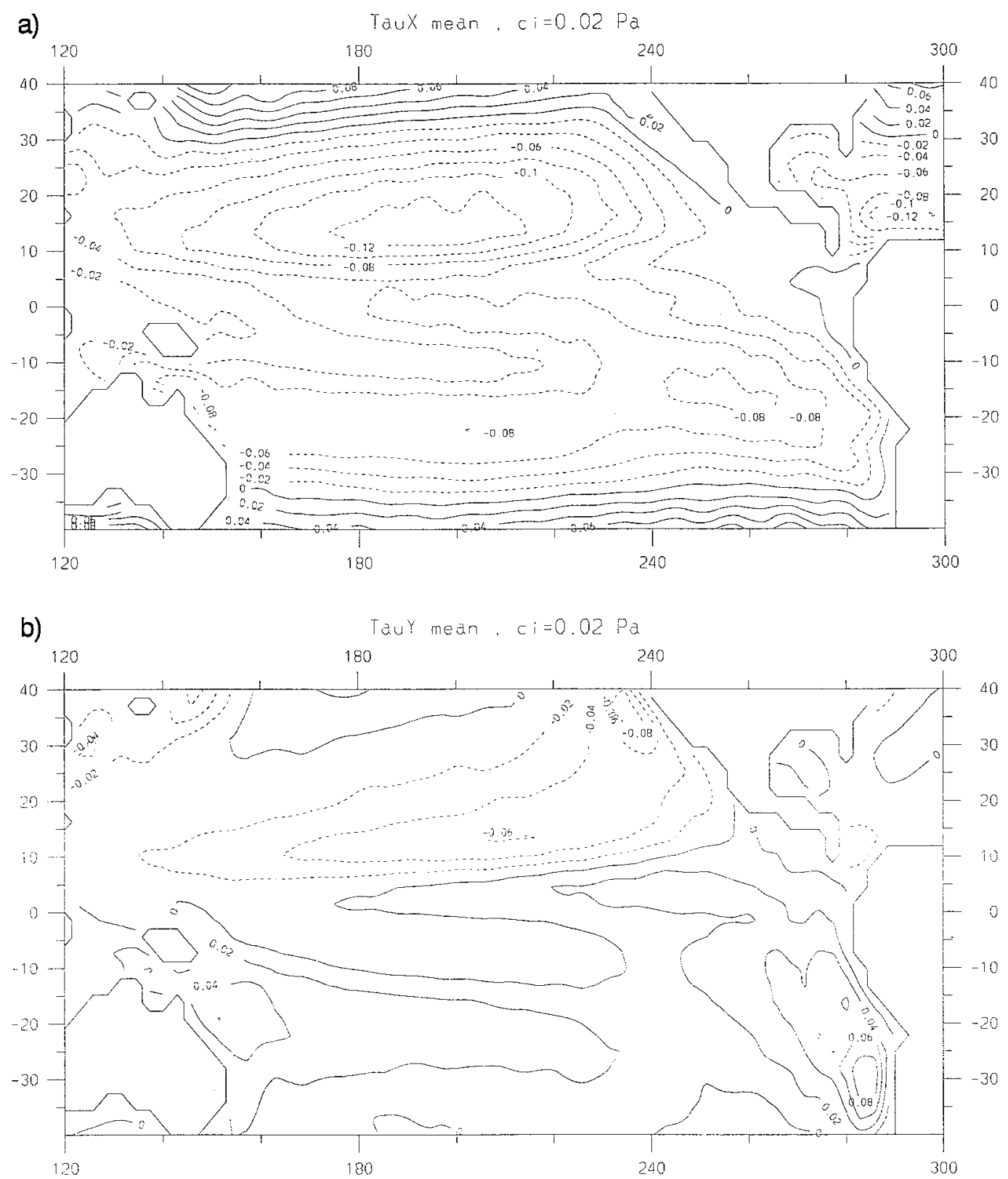

FIg. 4. Annual mean fields of tropical Pacific (a) zonal wind stress (Pa), (b) meridional wind stress (Pa), and (c) net surface solar radiation ( $\mathrm{W} \mathrm{m}^{-2}$ ) as simulated by ECHO-2. The contour intervals are $0.02 \mathrm{~Pa}, 0.02 \mathrm{~Pa}$, and $20 \mathrm{~W}$ $\mathrm{m}^{-2}$, respectively. Negative contours are dashed.

coasts in the earlier integration with ECHO-1, the errors are considerably reduced in our new run with ECHO-2, in which the errors reach hardly $2^{\circ} \mathrm{C}$.

This improvement can be traced back to the changes in the convection and radiation schemes of the atmosphere model. More stratus clouds are simulated by our atmosphere model, which strongly reduces the shortwave radiative flux at the air-sea interface. Typical shortwave radiative fluxes near the coast of South America, for instance, amount to typically $200 \mathrm{~W} \mathrm{~m}^{-2}$ in the integration with ECHO-2 (Fig. 4c), while they are at least $50 \mathrm{~W} \mathrm{~m}^{-2}$ larger in the simulation with ECHO-1. However, these numbers appear still too large compared to Oberhuber's (1988) climatology. The simulation with ECHO-2 shows cold biases at the equator in the Pacific centered near $120^{\circ} \mathrm{W}$ and in most parts of the midlatitudes. The cold bias along most of the Pacific's equator has many important consequences, as described below. While the cold biases in midlatitudes are slightly reduced in ECHO-2 relative to ECHO-1, the problems in the regions of the western boundary currents are not reduced in ECHO-2. 


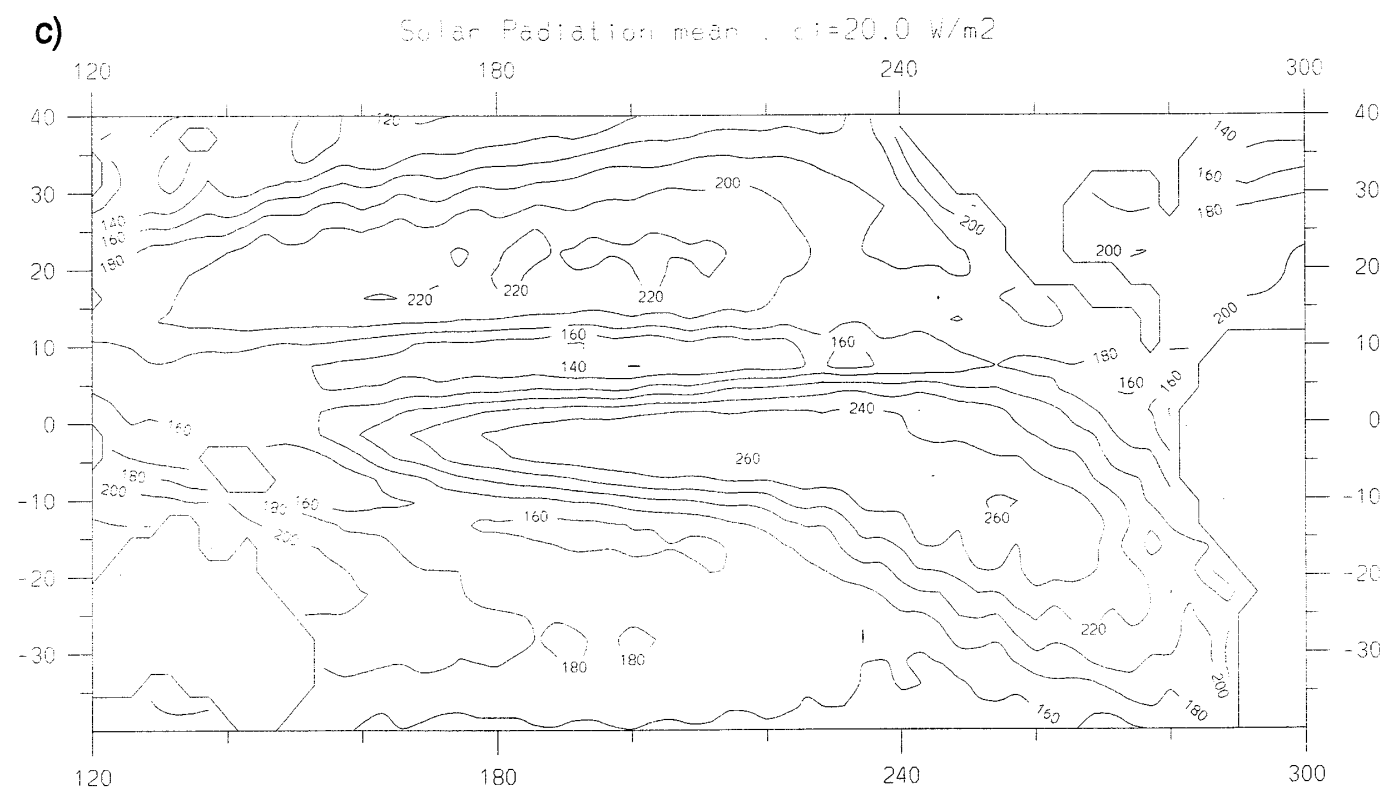

FIG. 4. (Continued)

We now turn to the tropical Pacific region for the remainder of this paper. The annual mean SST, precipipitation, and heat flux derived from the 10-yr run with ECHO-2 are shown in Fig. 3. These fields are simulated generally with more success than with ECHO-1 [for comparison see Latif et al. (1994) and Schneider et al. (1996)]. In contrast to ECHO-1, ECHO-2 does not simulate a double ITCZ and is able to reproduce a SPCZ (Fig. 3b). The orientation of the simulated SPCZ, however, is still significantly biased toward the equator. Improvements in both the atmosphere and ocean models are likely to contribute to the more realistic rainfall simulation. On the one hand, the atmosphere model now simulates realistically the rainfall patterns when run in an uncoupled mode, which is due to the improvements in the radiation and convection parameterizations. On the other hand, the warm pool-cold tongue structure is simulated with more success by the new version of the ocean model, since the numerical diffusion in the ocean model was reduced. The net surface heat flux at the airsea interface in the western equatorial Pacific is also improved, amounting now to about $20 \mathrm{~W} \mathrm{~m}^{-2}$ (Fig. 3c), as opposed to about $60 \mathrm{~W} \mathrm{~m}^{-2}$ in ECHO-1. The former figure is commonly believed to be the more realistic one. The annual mean wind stress is also simulated more realistically in ECHO-2 compared to ECHO-1. The zonal wind stress component is about twice as strong along the equator (Fig. 4a) relative to the simulation with ECHO-1, and the structure of the meridional wind stress component is more reasonable (Fig. 4b), as expected from the simulated rainfall pattern. Finally, the shortwave radiative flux entering the ocean is generally much smaller than in the simulation with ECHO-1 (Fig. 4c), especially in the stratus regions. Although coupled feed- backs still amplify the residual errors, the errors in the individual model components were reduced to an extent that keeps the coupled model in the correct climate regime.

The vertical structures of the temperatures and zonal currents along the equator within the upper $300 \mathrm{~m}$ are displayed in Fig. 5. Shown are instantaneous values at the end of year 5 with ECHO-2, which is a "normal" period. The thermocline is simulated reasonably well, with a realistic east-west tilt (Fig. 5a). Although the representation of the thermocline in the simulation with ECHO-2 is much better than in that with ECHO-1, it is still somewhat diffusive, especially in the western Pacific. Please note that the unstable temperature stratification is compensated for by the salinity stratification, with rather low salinities in the upper $100 \mathrm{~m}$ in the western Pacific (not shown).

The simulation of the Equatorial Undercurrent was also improved relative to ECHO-1, and the model undercurrent shows the correct orientation, but its strength is underestimated by about $20 \%$, and the eastward extension of the EUC core is not well simulated (Fig. 5b). A higher-order turbulent closure scheme for the description of vertical mixing processes might help to reduce these problems, as suggested by Blanke and Delecleuse (1993). The strong eastward surface currents in the western Pacific near $150^{\circ} \mathrm{E}$ are a transient feature and not representative for the long-term surface current climatology.

\section{Annual cycle}

The annual cycle in the tropical Pacific involves complex interactions between ocean and atmosphere. Since 
a)
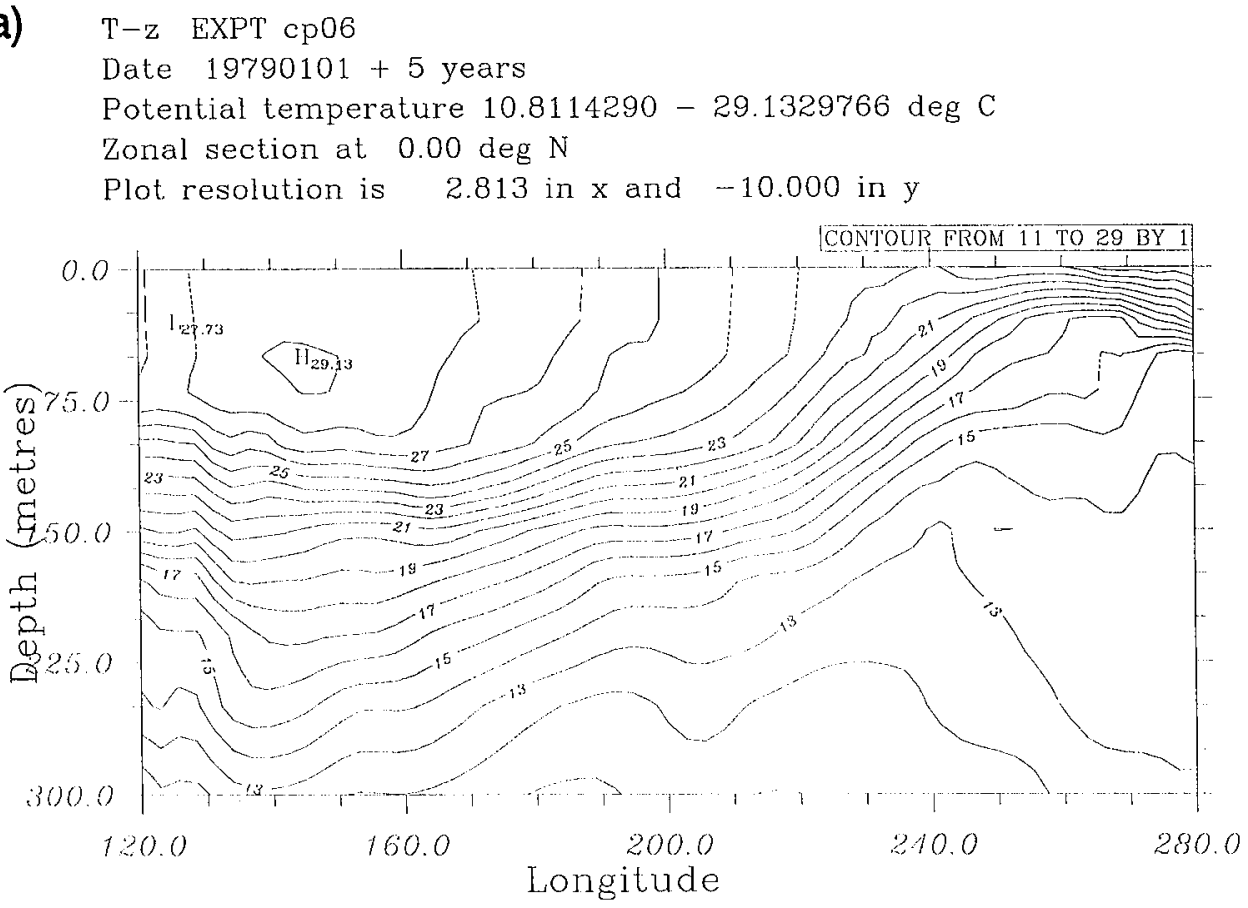

b) $\quad \mathrm{U}-\mathrm{z} \quad \mathrm{EXPT}$ cp06

Date $19790101+5$ years

U velocity $-0.6052377-1.0279105 \mathrm{~m} / \mathrm{s}$

Zonal section at $0.00 \mathrm{deg} \mathrm{N}$

Plot resolution is 2.813 in $\mathrm{x}$ and -10.000 in $\mathrm{y}$

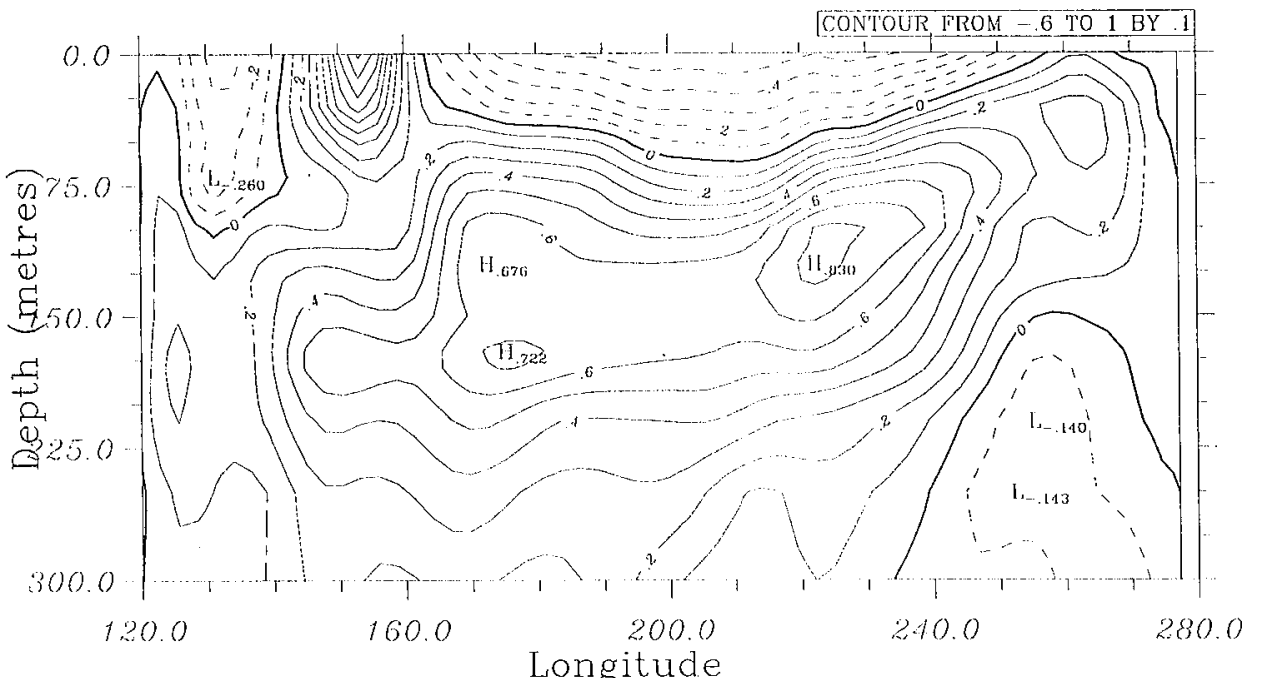

FIG. 5. Vertical sections of (a) temperatures $\left({ }^{\circ} \mathrm{C}\right)$ and (b) zonal currents $\left(\mathrm{m} \mathrm{s}^{-1}\right)$ along the equator as simulated by ECHO-2 at the end of year 5. The contour intervals are $1^{\circ} \mathrm{C}$ and $0.1 \mathrm{~m} \mathrm{~s}^{-1}$, respectively. Negative contours are dashed. 

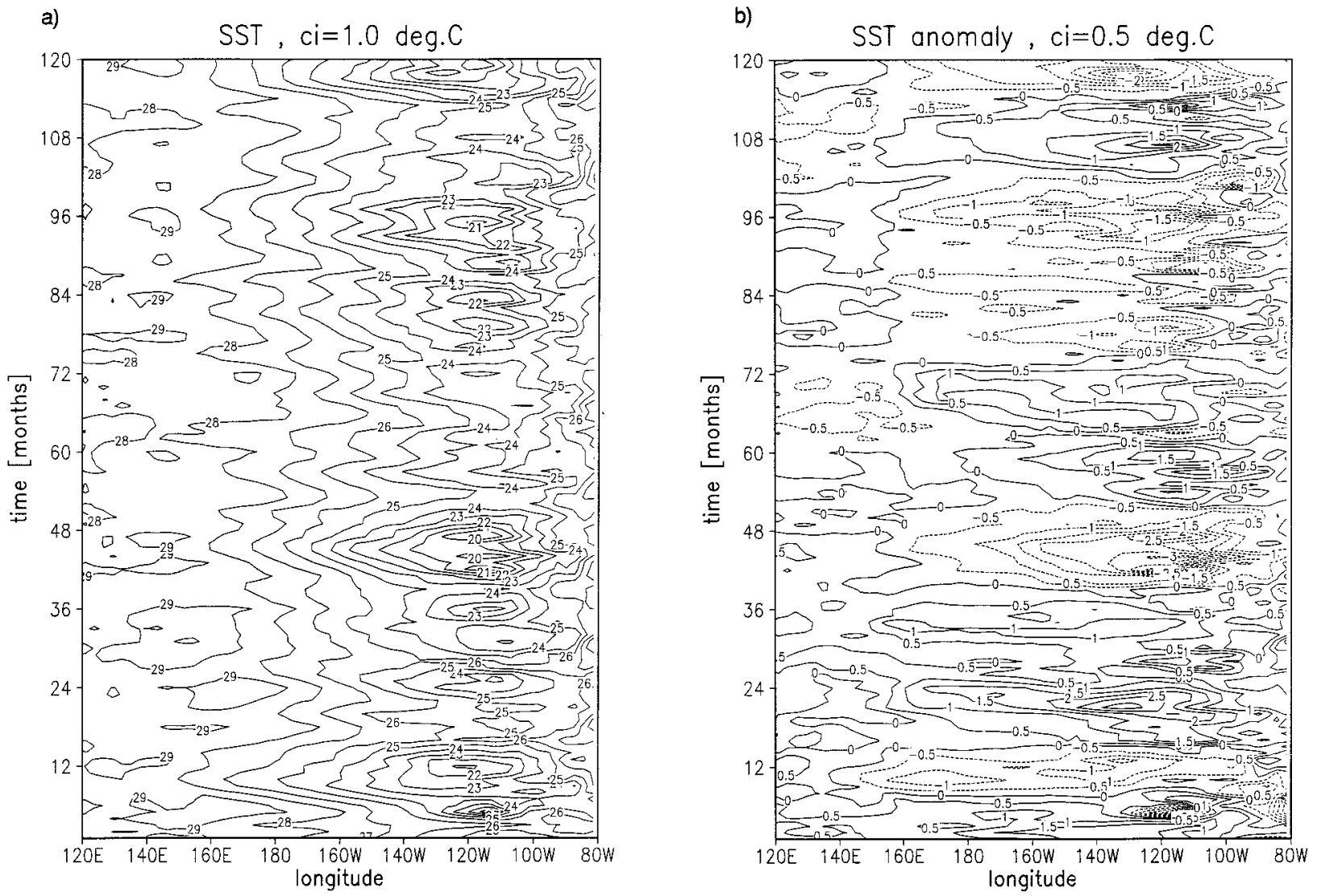

FIG. 6. Hovmoeller diagrams of equatorial Pacific (a) SST $\left({ }^{\circ} \mathrm{C}\right)$ and (b) SST anomalies $\left({ }^{\circ} \mathrm{C}\right)$ simulated during the 10-yr integration with ECHO-2. The contour intervals are $1^{\circ} \mathrm{C}$ and $0.5^{\circ} \mathrm{C}$, respectively. Negative contours are dashed.

the solar forcing at the equator has a semiannual cycle only, the existence of an annual cycle is an interesting problem. Many different physical processes are important in generating the annual cycle, such as mixing processes and upwelling dynamics in the ocean, heat transfer across the air-sea interface, or stratus cloud formation in the atmosphere. Thus, the simulation of the annual cycle is not only an ideal testbed for coupled ocean-atmosphere models but also for the physical parameterizations in the individual model components. As described above, numerous changes were made to the ECHAM and HOPE models. We believe, however, that the enhanced stratus cloud formation in our atmosphere model is the most important improvement with regard to the annual cycle. This is indicated in the intercomparison study of Mechoso et al. (1995) and supported by the experience at other institutes (e.g., S. G. H. Philander 1996, personal communication).

The time evolution of equatorial SST during the 10-yr integration with ECHO-2 is shown in Fig. 6a. The drift is relatively small, and there is no climate "crash" or "shock" in the beginning. The coupled model simulates a pronounced annual cycle in the eastern equatorial $\mathrm{Pa}$ cific (Figs. 6a and 7), with considerable intraseasonal and interannual variability superimposed (Fig. 6b).
Comparisons with observations are shown in Figs. 9 and 10 for the eastern (Nino-3) and western (Nino-4) equatorial Pacific, respectively. The eastern Pacific SST is characterized by a strong annual cycle and a high level of interannual variability, as witnessed by the SSTs observed during the period 1979-88 (Fig. 9). The phase of the annual cycle is simulated successfully by ECHO-2, although a weak residual semiannual cycle can be identified in the model simulation (Fig. 9b). The above-described cold bias is also clearly seen in the model simulation.

The western equatorial SST in the Nino-4 region (Fig. 10) is dominated by interannual variability. An annual cycle is virtually absent, and the seasonal evolution is characterized by a weak semiannual cycle (Fig. 10b). The model reproduces basically this behavior: seasonal variations are weak and interannual variations strong. However, a relatively strong fall cooling is simulated that is not observed. This unrealistic feature is due to the too strong equatorial cold tongue, which penetrates too far into the western Pacific in fall (Fig. 7b). The same model deficiency is also responsible for the overestimation of the interannual SST variability in the Nino-4 region (Fig. 10c).

The maps of tropical Pacific SST and precipitation 

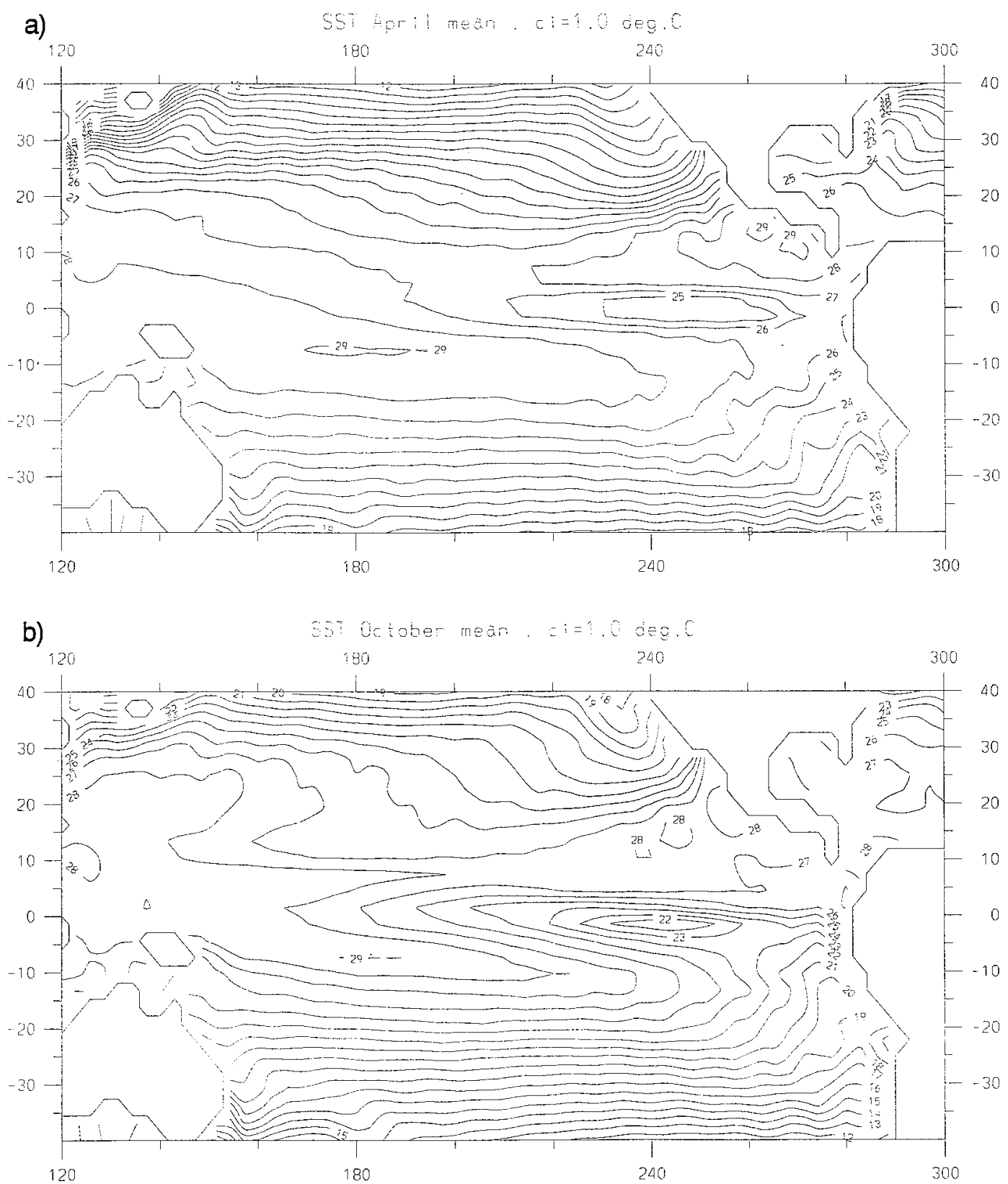

FIG. 7. Climatological tropical Pacific SSTs $\left({ }^{\circ} \mathrm{C}\right)$ for (a) April and (b) October as simulated by ECHO-2. The contour interval is $1^{\circ} \mathrm{C}$.

during the extreme months of the annual cycle, April and October, are displayed in Figs. 7 and 8. The observed seasonal westward propagation of the cold water, a feature that is described in many papers (e.g., Horel 1982), is clearly seen in the model simulation. This westward propagation arises from air-sea interactions similar to those described by Philander (1990) and Neelin (1991). The warm pool-cold tongue structure is simulated successfully in April. ECHO-2 simulates a much more zonally asymmetric SST pattern relative to our previous version of ECHO (Mechoso et al. 1995), with a considerably reduced eastward extension of the southern portion of the warm pool. The simulation of the October SSTs is less satisfying but still improved upon ECHO-1. The cold tongue cuts too far into the western Pacific, and the zonal extent of the northern portion of the warm pool is somewhat underestimated.

The seasonal evolution of the simulated precipitation is characterized by a meridional migration of the ITCZ in the eastern Pacific, reaching its most northern position in fall and its most southern position in spring (Fig. 8). There is a quite good correspondence between the po- 

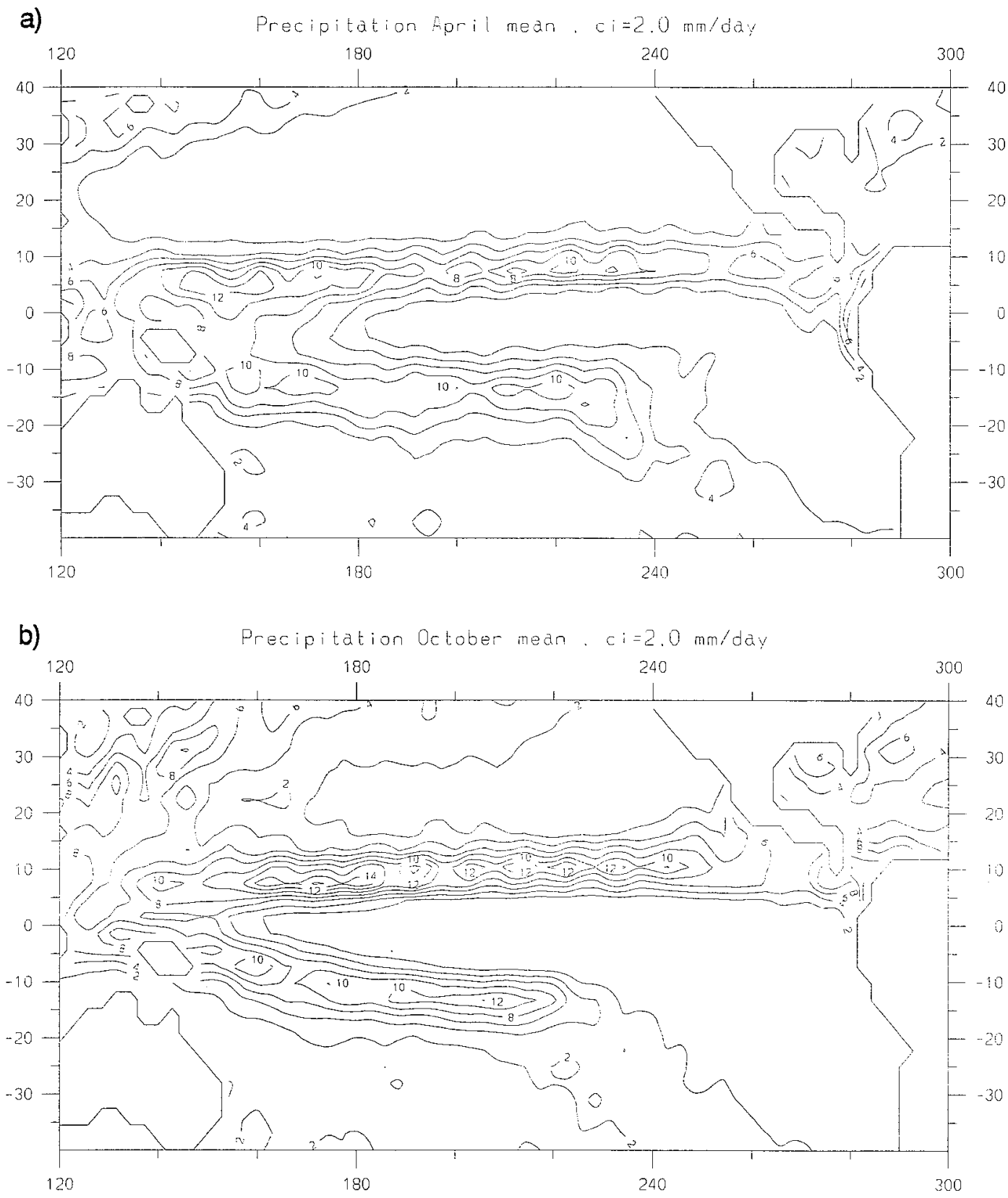

FIG. 8. Climatological tropical Pacific precipitation $\left(\mathrm{mm} \mathrm{day}^{-1}\right)$ for (a) April and (b) October as simulated by ECHO-2. The contour interval is $2 \mathrm{~mm} \mathrm{day}^{-1}$.

sition of the warmest water and that of the rainfall maximum in the eastern Pacific, as can be inferred from the corresponding Hovmoeller diagrams (Figs. 11a and 12a). Relatively strong rainfall is simulated in April in the western equatorial Pacific that extends to the dateline (Fig. 8a). This is unrealistic and arises from the too strong seasonal SST variability in the western Pacific (Fig. 10b). The rainfall over the western Pacific is more symmetric about the equator than over the eastern Pacific, with a minimum at the equator (Fig. 12b). A clear meridional propagation of the rainfall associated with the SPCZ is also simulated, with maximum rainfall in late boreal winter and early boreal spring near $10^{\circ} \mathrm{S}$.

\section{Interannual variability}

As mentioned above, the 10 -yr run with our new CGCM ECHO-2 is definitely too short to assess completely the interannual variability of the coupled model. However, several points pertaining to the model's performance of interannual variability are already obvious, and we believe that it is worth pointing these out. The 
a) SST NINO-3 , cp06

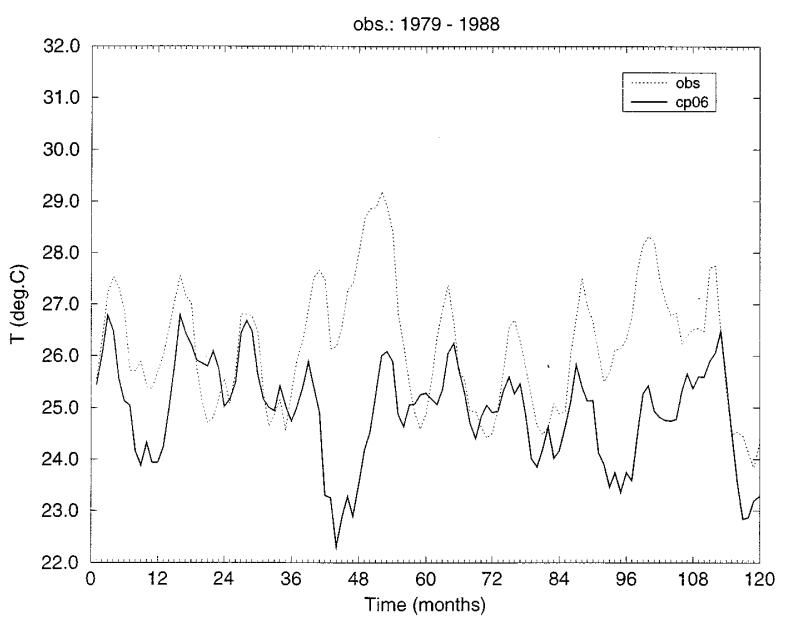

c)

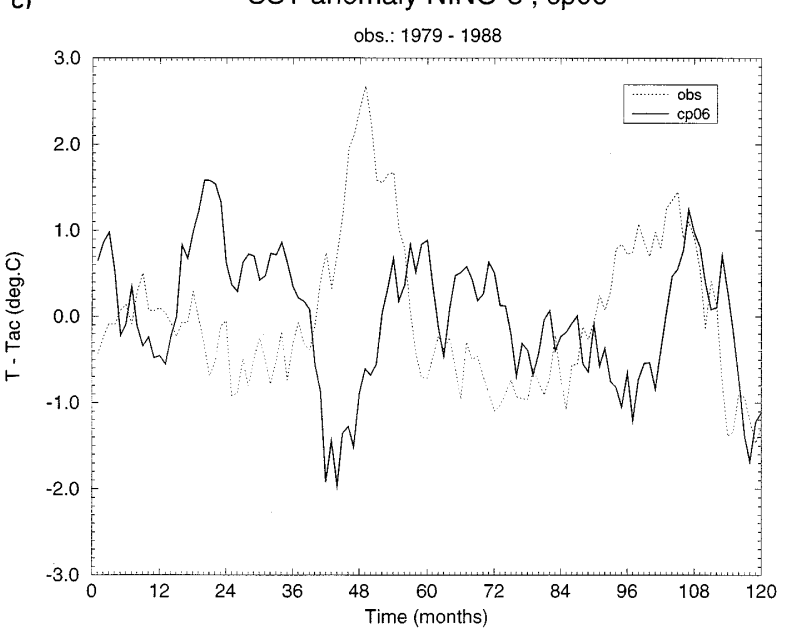

b)

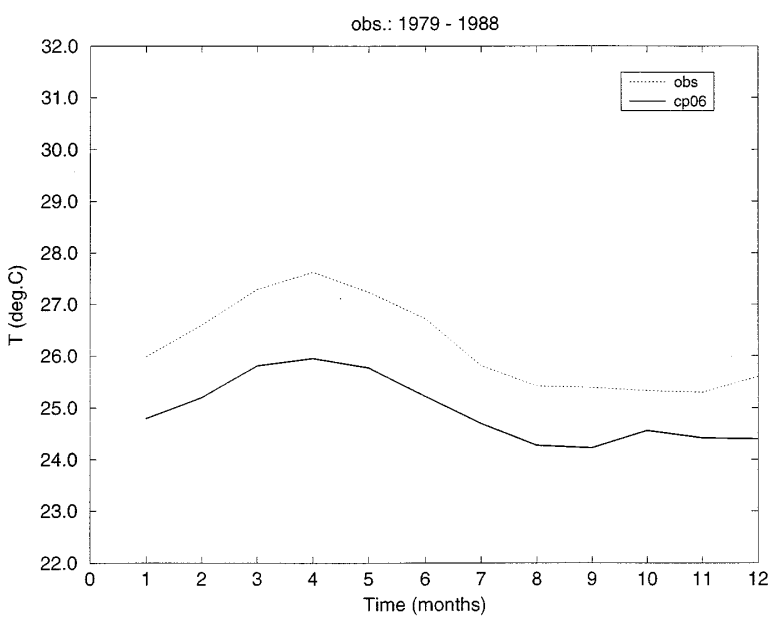

FIG. 9. Time series of Nino-3 SSTs $\left({ }^{\circ} \mathrm{C}\right)$ : (a) full values, (b) climatological annual cycles, and (c) anomalies relative to the climatological annual cycles shown in (b). The coupled model results are shown as thick solid lines, whereas the observations for the period 1979-88 are shown for comparison as thin dotted lines. most apparent difference between the simulation and the previous version ECHO- 1 is the strongly enhanced level of interannual variability in the tropical Pacific. ECHO-2 simulates, for instance, rather strong SST anomalies in the eastern equatorial Pacific (Figs. 6b, 9c, and 13a). Such strong SST anomalies were not simulated during the whole 125-yr integration with ECHO-1. This behavior was already expected from the uncoupled experiments with our new ocean model HOPE-2 (Fig. 1) and results from the better simulation of the thermocline, which is now much sharper than that simulated by HOPE-1. The change in the numerical treatment of the tracer advection resulted in considerably less effective mixing and inhibited an erosion of the thermocline (Fig. 5a). The SST is now more sensitive to thermocline perturbations, and this enhanced the interannual variability in the coupled run with ECHO-2. The changes made to the atmosphere model are probably less important in determining the interannual variability. Preliminary results indicate that the mechanism leading to the interannual variability appears to be related to the subsurface memory of the system.

We display the spatial structures of anomalous SST, zonal wind stress, and freshwater flux in Figs. 13 and 14. To enhance the signals, we show differences between the warm phase of year 2 and the cold phase of year 4 . Overall, the anomaly structures are simulated reasonably well, with SST anomalies centered in the eastern equatorial Pacific (Fig. 13a), accompanied by westerly wind stress anomalies in the western equatorial Pacific (Fig. 14a) and equatorward migrations of the ITCZ and SPCZ (Fig. 14b). There are, however, some important differences to observations. We show in Fig. 13b for comparison the difference of SST anomalies observed during the warm event 1972 and the cold event 1973, a period with a similar level of interannual variability. The simulated SST anomalies are too much equatorially confined, and they extend too much into the western Pacific (Fig. 13a). The latter deficiency is related to the too strong cold tongue, which extends also too far into the western 

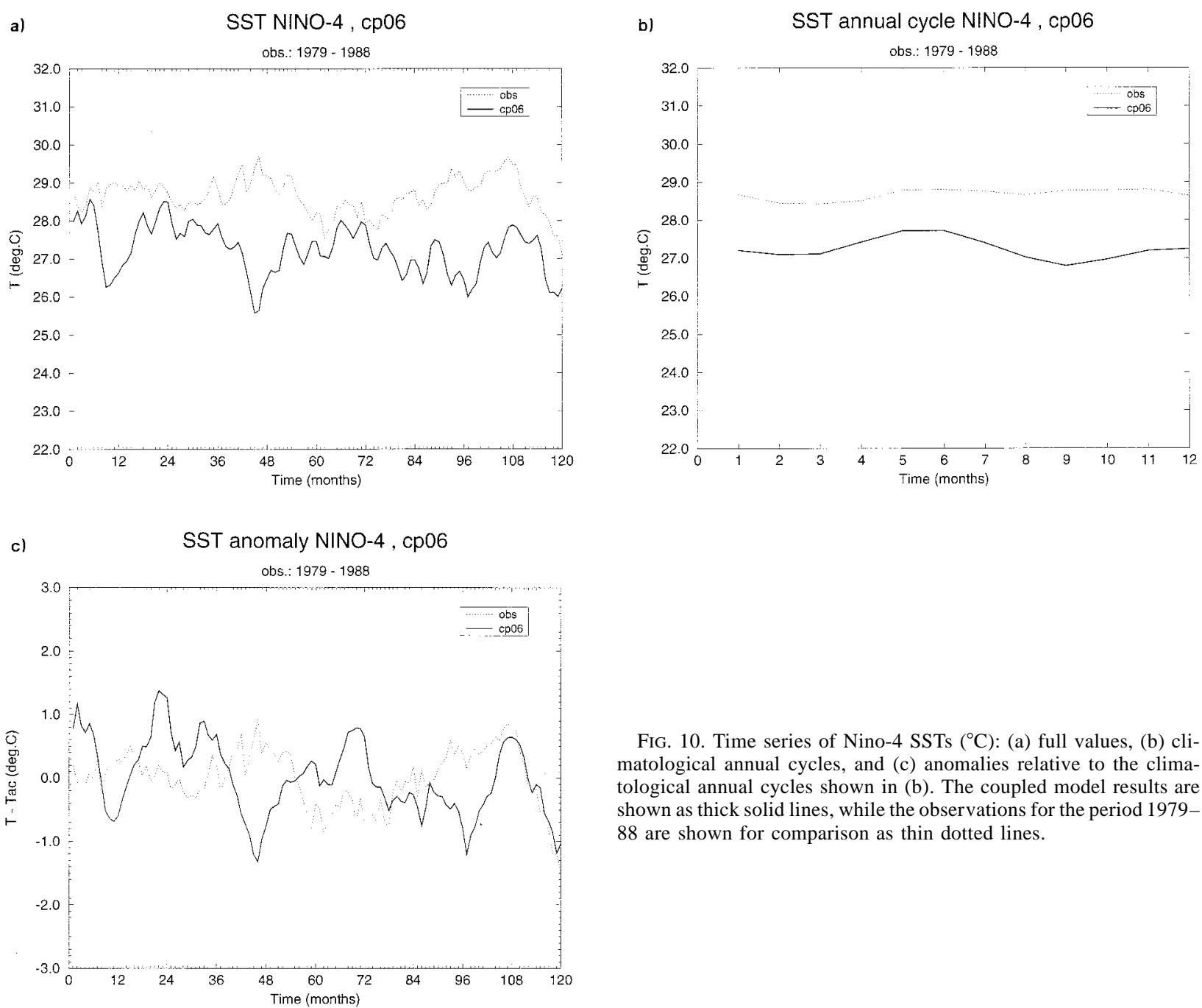

FIG. 10. Time series of Nino-4 SSTs $\left({ }^{\circ} \mathrm{C}\right.$ ): (a) full values, (b) climatological annual cycles, and (c) anomalies relative to the climatological annual cycles shown in (b). The coupled model results are shown as thick solid lines, while the observations for the period 197988 are shown for comparison as thin dotted lines.

Pacific (Fig. 3a). Furthermore, the coupled model does not simulate the SST anomalies near the eastern boundary in both hemispheres, especially in the southeastern Pacific and apparently fails to reproduce the characteristic off-equatorial SST anomalies of opposite sign. This latter problem might be, however, at least partly due to the initial spinup of the model. Although the reasons for the other errors are unclear, they seem to be inherent to the ocean model, since the problems in simulating the ENSOrelated SST anomalies occur also in uncoupled runs with our ocean model HOPE-2 forced by observed wind stresses. The problems seem to be also common to most other ocean GCMs (e.g., J. Shukla 1996, personal communication). Finally, the simulated freshwater anomalies indicate that precipitation anomalies do not propagate sufficiently eastward (Fig. 14b), which is probably also due to the ocean model's cold temperature bias in the western Pacific, because our atmosphere model ECHAM-4 simulates realistically the ENSO-related pre-

cipitation anomalies when run in an uncoupled mode forced by observed SSTs.

\section{Discussion}

We have developed a new version of our coupled general circulation model ECHO, referred to as ECHO-2. We have shown that considerable progress was made by improving the individual model components. Both the performance of the annual cycle and interannual variability are improved considerably in the new coupled model. In particular, the annual cycles of SST and precipitation in the eastern Pacific are simulated realistically in ECHO-2. Probably the two most important changes made are the enhanced stratus cloud cover in the atmosphere model and the better representation of the thermocline in the ocean model. Many coupled runs would be needed in order to prove this statement rigorously, but this is a too expensive ap- 

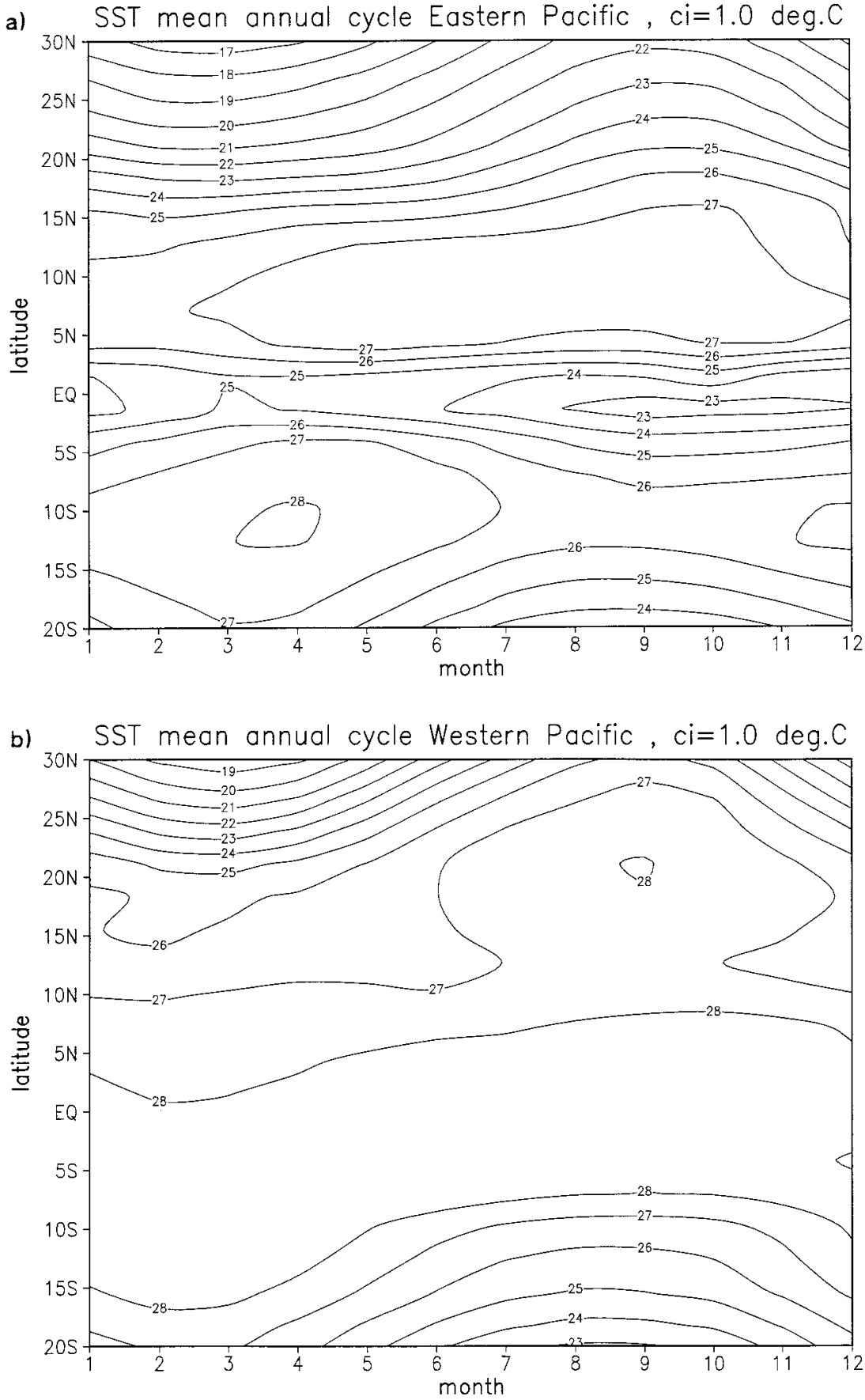

FIg. 11. Mean annual cycle of SSTs $\left({ }^{\circ} \mathrm{C}\right.$ ) between $20^{\circ} \mathrm{S}$ and $30^{\circ} \mathrm{N}$ in the (a) eastern Pacific $\left(100^{\circ}-150^{\circ} \mathrm{W}\right)$ and (b) western Pacific $\left(140^{\circ} \mathrm{E}-180^{\circ}\right)$ as simulated by ECHO-2. The contour intervals are $1^{\circ} \mathrm{C}$.

proach. When we analyzed the behavior of our previous version, ECHO-1, and compared it to other coupled GCMs (Latif et al. 1994; Mechoso et al. 1995), we already speculated that the problems with the stratus clouds and the thermocline were responsible for some of the major shortcomings at that time. It is gratifying that improvements in these two problem areas indeed led to significant improvements in the coupled simulation with ECHO-2.

Furthermore, the individual model components were tuned independently. It was the ECAHM-3 fluxes that were used in the development of the new version of the ocean model HOPE-2. If anything, the ocean model is tuned to the previous atmosphere model ECHAM-3 

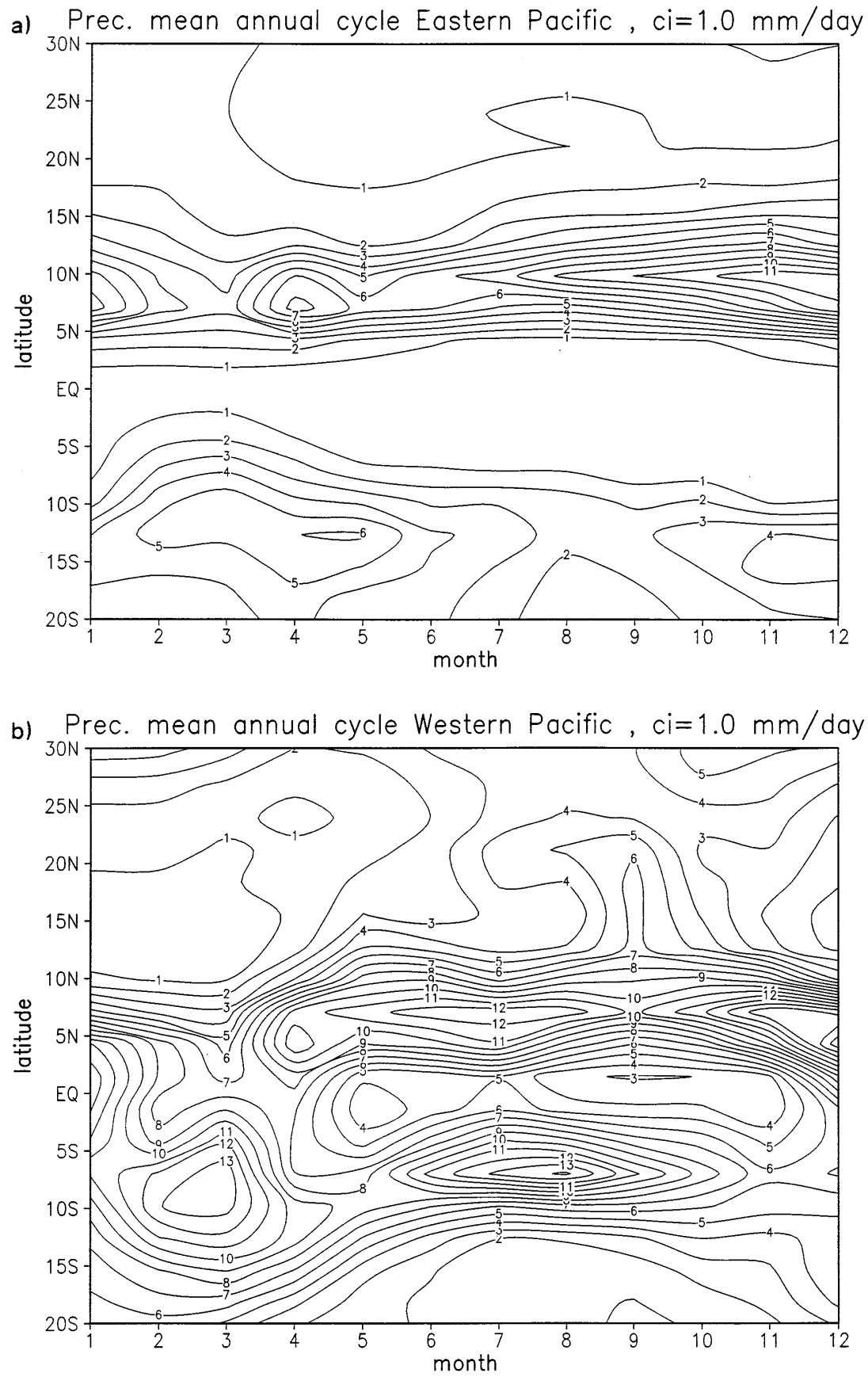

FIG. 12. Mean annual cycle of precipitation $\left(\mathrm{mm} \mathrm{day}^{-1}\right)$ between $20^{\circ} \mathrm{S}$ and $30^{\circ} \mathrm{N}$ in the (a) eastern Pacific $\left(100^{\circ}-150^{\circ} \mathrm{W}\right)$ and (b) western Pacific $\left(140^{\circ} \mathrm{E}-180^{\circ}\right)$ as simulated by ECHO- 2 . The contour intervals are $1 \mathrm{~mm}$ day $^{-1}$.

rather than ECHAM-4, which we used in the coupled integration with ECHO-2. Indeed, when we used the same ocean model (HOPE-2) and coupled it to ECHAM-3 the overall performance was worse than the one described here, although still somewhat better relative to ECHO-1. Thus, the improved performance gives us hope that we are making real improvements, rather than hiding problems by tuning one component to compensate for errors in the other.

There are, however, still some significant problems that need to be addressed in further developments. The model simulation exhibits cold biases along most of the equator and in midlatitudes. It is likely that either errors in the net surface radiation balance at the air-sea in- 


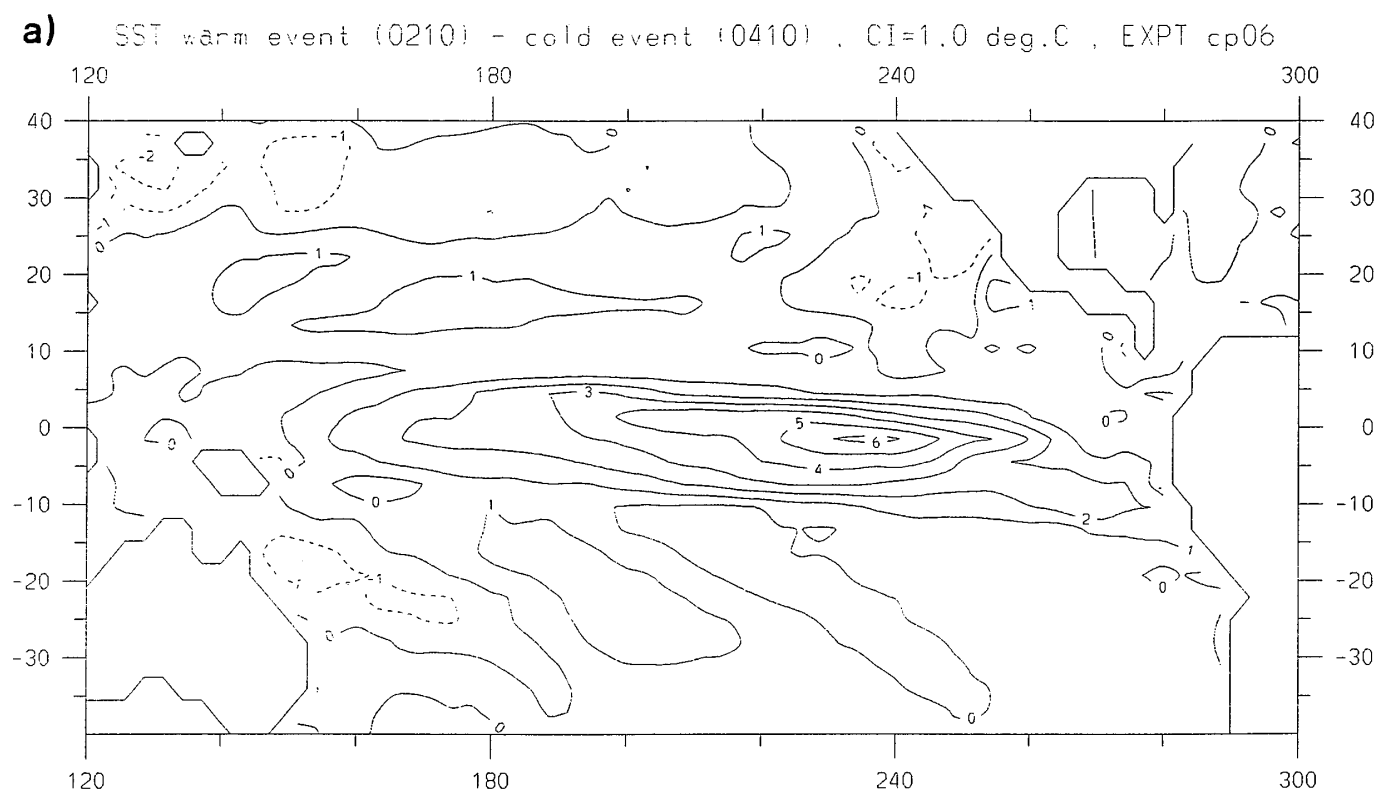

b) SST warm event 17211 ) - cold event (7311), CI=1.0 deg.C, observations

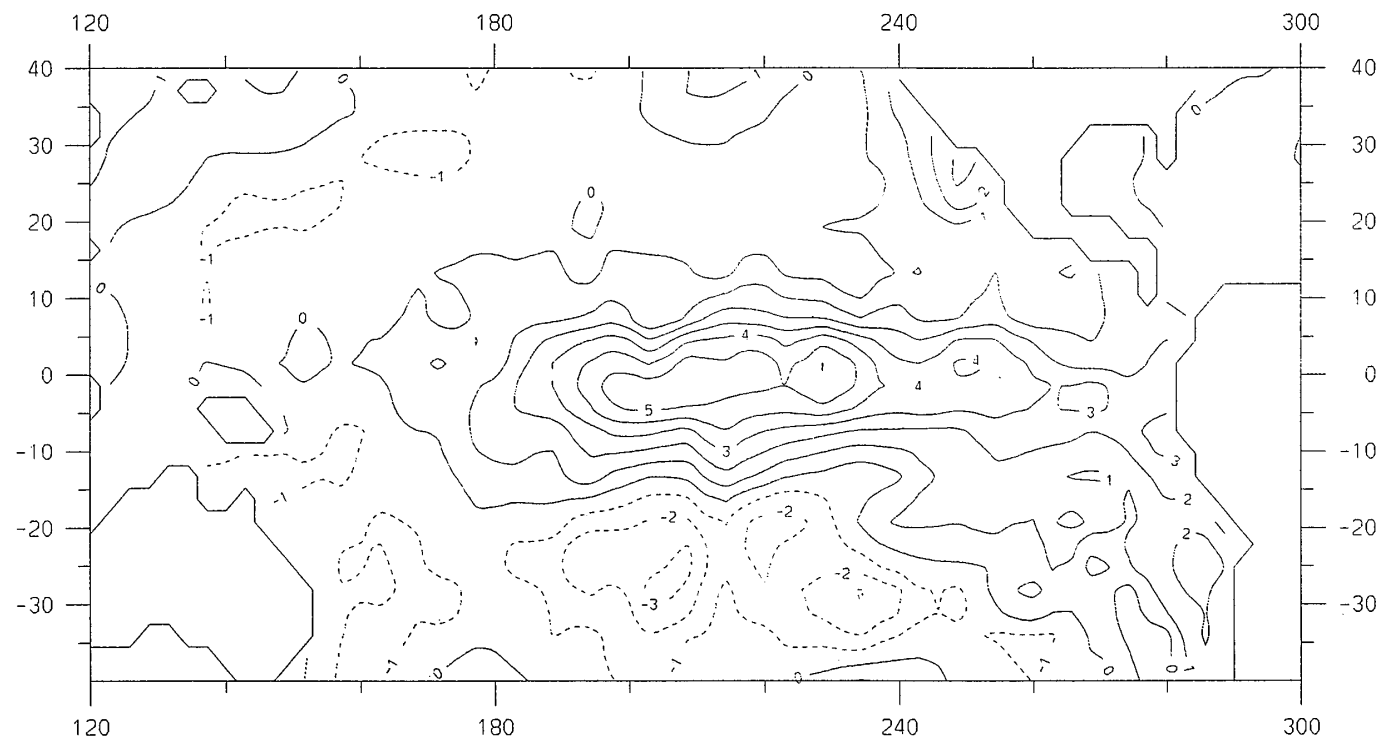

FIG. 13. (a) Difference in October SSTs $\left({ }^{\circ} \mathrm{C}\right)$ between the warm event of year 2 and the cold event of year 4 as simulated by ECHO-2. (b) Difference in November SSTs observed during the warm event of 1972 and the cold event of 1973 . The contour intervals are $1^{\circ} \mathrm{C}$. Negative contours are dashed.

terface, artificially high vertical mixing in the ocean, or a combination of both cause these cold biases. Part of the problem in the equatorial Pacific, however, seems to be entirely related to problems with the ocean model.

The simulation of interannual variability is also far from being perfect, and the errors can be traced back mainly to the ocean model. We shall therefore implement a new higher-order vertical mixing scheme into the next HOPE version. Finally, the inclusion of a sea ice model is still pending. The incorporation of a sea ice model is under way and first test runs are being conducted.

Acknowledgments. We would like to thank Prof. Dr. L. Bengtsson and his group, in particular Dr. E. Roeckner and Mr. U. Schlese for developing and providing the ECHAM-4 model, Dr. E. Maier-Reimer for helping in developing HOPE-2, and Dr. Klaus Arpe for many fruitful discussions. This work was supported by the 


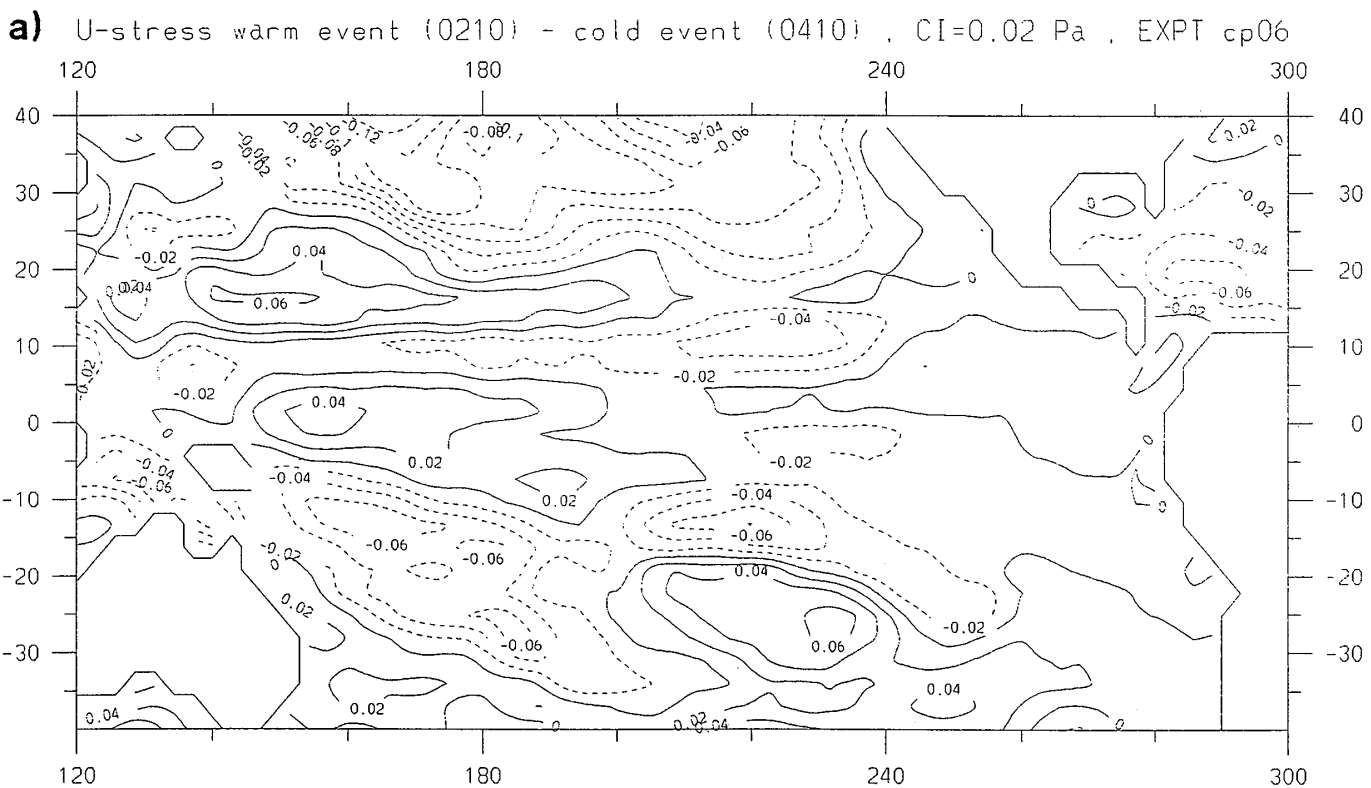

b) P-E warm event $(0210 !$ - cold event 10410$)$. CI=2.0 mm/day, EXPT cp06

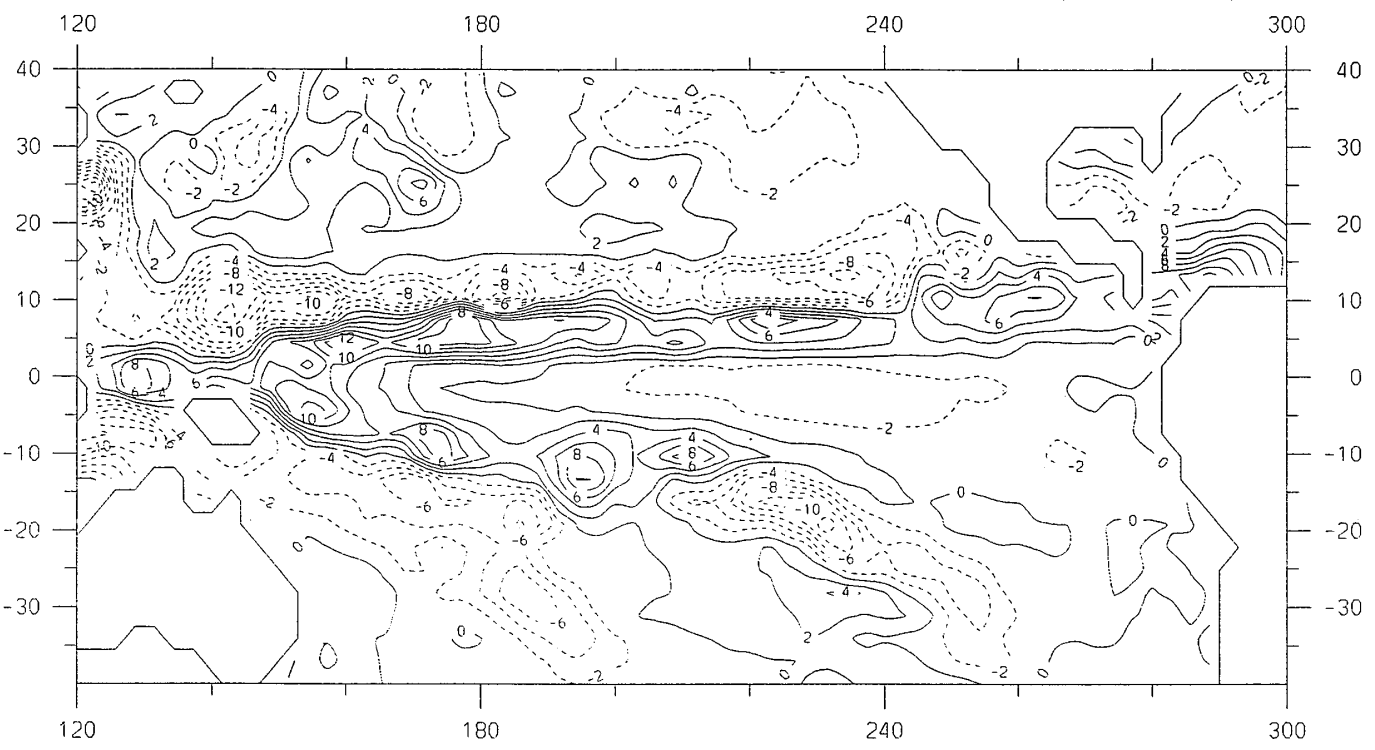

FIG. 14. Difference in October (a) zonal wind stress (Pa) and (b) freshwater flux ( $\left.\mathrm{mm} \mathrm{day}^{-1}\right)$ between the warm event of year 2 and the cold event of year 4 as simulated by ECHO-2. The contour intervals are $0.02 \mathrm{~Pa}$ and $2 \mathrm{~mm}$ day $^{-1}$, respectively. Negative contours are dashed.

Bundesminister für Forschung und Technologie under Grant 07 VKO1/1 and the European Union under Grant EV5V-CT94-0507.

\section{REFERENCES}

Blanke, B., and P. Delecleuse, 1993: Variability in the tropical Atlantic Ocean simulated by a general circulation model with two different mixed-layer physics. J. Phys. Oceanogr., 23, 1363-1388.

Brinkop, S., and E. Roeckner, 1995: Sensitivity of a general circulation model to parameterizations of cloud-turbulence interactions in the atmospheric boundary layer. Tellus, 47A, 197-220.
Chang, P., B. Wang, T. Li, and L. Ji, 1994: Interactions between the seasonal cycle and the Southern Oscillation-Frequency entrainment and chaos in a coupled ocean-atmosphere model. Geophys. Res. Lett., 21, 2817-2820.

Dijkstra, H. A., and J. D. Neelin, 1995: Ocean-atmosphere interaction and the tropical climatology. Part II: Why the Pacific cold tongue is in the east. J. Climate, 8, 1343-1359.

DKRZ, 1995: Das Klimamodell ECHAM-4, 169 pp. [Available from Deutsches Klimarechenzentrum, Bundesstr. 55, D-20146 Hamburg, Germany.]

Horel, J. D., 1982: On the annual cycle of the tropical Pacific atmosphere and ocean. Mon. Wea. Rev., 110, 1863-1878.

Jin, F.-F., J. D. Neelin, and M. Ghil, 1994: El Niño on the devil's 
staircase: Annual subharmonic steps to chaos. Science, 264, $270-272$.

Latif, M., and T. P. Barnett, 1994: Causes of decadal climate variability over the North Pacific and North America. Science, 266, 634-637.

—, T. Stockdale, J. O. Wolff, B. Burgers, E. Maier-Reimer, M. M. Junge, K. Arpe, and L. Bengtsson, 1994: Climatology and variability in the ECHO coupled GCM. Tellus, 46A, 351-366.

Levitus, S., 1982: Climatological atlas of the world ocean. NOAA Prof. Paper No. 13, 173 pp, 17 microfiche. [Available from U.S Govt. Printing Office, Washington, D.C. 20402.]

Mechoso, M. R., and Coauthors, 1995: The seasonal cycle over the tropical Pacific in coupled ocean-atmosphere general circulation models. Mon. Wea. Rev., 123, 2825-2838.

Morcrette, J.-J., 1991: Radiation and cloud radiative properties in the European Centre for Medium-Range Weather Forecasts forecasting system. J. Geophys. Res., 96, 9121-9132.

Neelin, J. D., 1991: The slow sea surface tempertaure mode and the fast wave limit: Analytic theory for tropical interannual oscillations and experiments in a hybrid coupled model. J. Atmos. Sci., 48, 584-606.

—, and Coauthors, 1992: Tropical air-sea interactions in general circulation models. Climate Dyn., 7, 73-104.

Nordeng, T. E., 1997: Extended versions of the convective parameterization scheme at ECMWF and their impact on the mean and transient activity of the model in the Tropics. Quart. J. Roy. Meteor. Soc., in press.

Oberhuber, J. M., 1988: An atlas based on the COADS dataset: The budgets of heat, bouyancy, and turbulent kinetic energy at the surface of the global ocean. Max-Planck-Institut für Meteorol- ogie Rep. No. 15, 20 pp. [Available from Max-Planck-Institut, Bundesstr. 55, D-20146 Hamburg, Germany.]

Philander, S. G. H., 1990: A review of simulations of the Southern Oscillation. International TOGA Scientific Conf. Proc., Honululu, HI, World Meteor. Org., 87-94.

Roeckner, E., 1995: Parameterization of cloud radiative properties in the ECHAM4 model. Proc. WCRP Workshop on "Cloud Microphysics Parameterizations in Global Atmospheric Circulation Models, ' Kananaskis, Alberta, Canada, World Meteor. Org., 105-116.

— , and K. Arpe, 1995: AMIP-experiments with the new MaxPlanck-Institut model ECHAM-4. AMIP Scientific Conf. Proc., Monterey, CA, AMIP, 307-312.

- J. M. Oberhuber, A. Bacher, M. Christoph, and I. Kirchner, 1996: ENSO variability and atmospheric response in a global coupled atmosphere-ocean GCM. Climate Dyn., 12, 737-754.

Schneider, N., T. P. Barnett, M. Latif, and T. Stockdale, 1996: Warm pool physics in a coupled GCM. J. Climate, 9, 219-239.

Slingo, J., 1987: Development and verification of a cloud prediction scheme for the ECMWF model. Quart. J. Roy. Meteor. Soc., 113, 899-928.

Stockdale, T., M. Latif, G. Burgers, and J. O. Wolff, 1994: Some sensitivities of a coupled ocean-atmosphere GCM. Tellus, 46A, 367-380.

Tzippermann, E., L. Stone, H. Jarosh, and M. A. Cane, 1994: El Niño chaos: Overlapping of resonances between the seasonal cycle and the Pacific ocean-atmosphere oscillator. Science, 264, 7274.

Xie, S. P., and S. G. H. Philander, 1994: A coupled ocean-atmosphere model of relevance to the ITCZ in the eastern Pacific. Tellus, 46A, 340-350. 